\title{
Al-Razi and Islamic medicine in the 9th century
}

\author{
Selma Tibi
}

J R Soc Med 2006;99:206-207

Additional material for this article is available from The James Lind Library website [www.jameslindlibrary.org] where this paper was previously published.

Although Baghdad was only 50 years old in the 9th century, it was at the peak of its political power; a powerhouse of learning and the leading medical centre of the time. It was there that many important Greek works were translated into Arabic, including Dioscorides's Materia medica, which formed the basis for Arabic pharmacology. While Islamic physicians revered Greek medicine and seldom questioned it, they began to add comments and to contribute views in the 9th century CE, and observations of their own.

Of the physicians who worked in Baghdad during this era, one stands out as quite exceptional. Abu Bakr Muhammad ibn Zakariyya al-Razi (865-925 CE; 251-313 AH) - known to the Latin world as Rhazes - was so called after the place where he was born and died-Rayy, near Tehran. Alone among his contemporaries, al-Razi specifies all his sources, which are divided almost equally between Islamic writers and the ancient Greeks (particularly Galen). He is thus an invaluable source of earlier, often lost, works.

Al-Razi was a musician and a money-changer until his 30s, when he began to study medicine in Baghdad. He went on to become one of the greatest physicians of the medieval period, writing over 200 works; half of them on medicine, but others on topics that included philosophy, theology, mathematics, astronomy and alchemy.

The largest and most important of al-Razi's medical works is Kitab al-Hawi fi al-tibb ${ }^{1}$ (The comprehensive book of medicine), a collection of medical notes that al-Razi made throughout his life in the form of extracts from everything he had read, as well as observations from his own medical experience. Translated into Latin in the 13th century, Kitab al-Hawi was repeatedly printed in Europe during the 15th and 16th centuries under the title Liber Continens.

Printed as it was when printing was new, al-Razi's writings had a major influence on the development of medical practice in Europe.

The Kitab al-Hawi is an enormous work: in its published form it consists of 23 volumes, two of which are further divided into two lengthy parts. Each volume deals with

Risinghurst, Oxford OX3 8JD, UK

E-mail: selmaharb@yahoo.co.uk specific parts or diseases of the body, although the groupings of ailments are often idiosyncratic. The volume that includes gout, for example, also covers diseases related to large and small worms in the abdomen, piles, hunchback, varicose veins and elephantiasis. Amongst these massive files of working notes are to be found the occasional case history, as well as a glimpse of al-Razi as a practising clinician (a collection of over 900 case histories recorded by some of his students and issued posthumously exists under the title The Book of Experience or Casebook).

Some of al-Razi's ideas have parallels with ideas today. For example, he suggests that:

'The physician, even though he has his doubts, must always make the patient believe that he will recover, for the state of the body is linked to the state of the mind.'

He cautioned against unnecessary use of drugs, and particularly polypharmacy:

'If the physician is able to treat with nutrients, not medication, then he has succeeded. If, however, he must use medication, then it should be simple remedies and not compound ones'.

Unlike the polypharmacy promoted by some other Islamic authors in the 9th century, al-Razi rarely recommends compound remedies, and when he does, these have few ingredients.

All the leading physicians of Baghdad used medicines whose beneficial effects had been identified during the classical period. For example, they used opium in a variety of forms, both external and internal, for ailments and conditions in every part of the body, especially where pain was involved. ${ }^{2}$ Opium was considered particularly effective for diseases of the intestines and of the eyes, but it also featured in a number of remedies to treat gout and painful joints.

The inflammation of joints associated with gout might explain why ancient Greek physicians described the condition under various names, which they appear to have applied to gout and rheumatism alike. Al-Razi gives four recipes for 'gout and the joints' in Kitab al-Hawi. All of these are pastes or dressings to be applied to the painful areas with, in one instance, a damp piece of paper or cloth 
to keep the medication moist. Opium occurs in all of them, henbane in one and hemlock in two - one of which also has mandrake. A paste that al-Razi describes as good contains equal parts of opium and liquid storax (Liquidambar orientalis).

Three of al-Razi's four remedies for gout and the joints include colchicum, which had been used for treating gout since at least the second millennium BCE. Indeed, its active ingredient, colchicine, is still used to treat acute attacks of the condition today.

'Where gout is accompanied by high fever, the recipe contains seeds that cause diuresis without giving out much heat, such as those of white colchicum, water melon and cucumber. These, in equal parts, are mixed with one third of a part of opium, and an oral dose of four dirhams $(12 \mathrm{~g})$ of the mixture with the same amount of sugar is analgesic and effective within the hour.'

'Where there is no high fever, the ingredients, in an oral remedy, are: colchicum, opium, borax, colocynth, ammi, aristolochia, and mountain thyme.'

One of the two recipes illustrates a common feature of al-Razi's writings: he makes clear that he was not prepared simply to accept what he read, but wished to reserve judgement about the effects of medicines until he had investigated them personally.

'I have heard amazing accounts, amongst which is the following: the physician of . . . prescribed for gout a potion prepared with two mithqals (4.5 g) of colchicum, half a dirham $(1.5 \mathrm{~g})$ of opium and three dirhams $(9 \mathrm{~g})$ of sugar. The drug is said to be effective within the hour, but I need to verify this.'

Al-Razi's willingness to test the validity of therapeutic claims and theories in practice is illustrated in another passage in Kitab al-Hawi. He identified the symptom complex that heralded the onset of meningitis - dullness and pain in the head and neck, the avoidance of bright light (photophobia), insomnia and exhaustion - and wondered how best to treat these patients:

'When the dullness (thiqal) and the pain in the head and neck continue for three and four and five days or more, and the vision shuns light, and watering of the eyes is abundant, yawning and stretching are great, insomnia is severe, and extreme exhaustion occurs, then the patient after that will progress to meningitis (sirsâm) . . . If the dullness in the head is greater than the pain, and there is no insomnia, but rather sleep, then the fever will abate, but the throbbing will be immense but not frequent and he will progress into a stupor (lithûrghas). So when you see these symptoms, then proceed with bloodletting. For I once saved one group [of patients] by it, while I intentionally neglected [to bleed] another group. By doing that, I wished to reach a conclusion (ra'y). And so all of these [latter] contracted meningitis.'

Although we would be unlikely to recommend bloodletting for patients with the prodromal symptoms of meningitis today on the basis of this evidence, al-Razi's approach to refining his treatment reflects a way of thinking about one of the principles to be observed in drawing inferences about the effects of treatments, namely, the need for comparison.

Acknowledgments I am grateful to Emilie Savage-Smith for identifying passages in Al-Razi's work which are relevant to the objectives of the James Lind Library, and for her input in to an earlier draft of this commentary.

\section{REFERENCES}

1 Al-Razi. Kitab al-Hawi fi al-tibb. Oxford Bodleian MS Marsh 156, fol. 167a lines 6-12 (also on page 122 in Volume 15 of the 1st edition of the 23-volume set of the book. Hyderabad: Osmania Oriental Publications Bureau, Osmania University, 1955-7)

2 Tibi S. The Medicinal Use Of Opium In Ninth-Century Baghdad. Leiden: Brill, 2005 